\title{
Hubungan Psikologis Ibu Hamil dengan Kejadian Hiperemesis Gravidarum
}

\author{
Jessica F. Rorrong, ${ }^{1}$ John J. E. Wantania, ${ }^{2}$ Anastasia M. Lumentut ${ }^{2}$
}

\author{
${ }^{1}$ Program Studi Pendidikan Dokter Fakultas Kedokteran Universitas Sam Ratulangi, Manado, \\ Sulawesi Utara, Indonesia \\ ${ }^{2}$ Bagian Ilmu Kebidanan dan Kandungan Fakultas Kedokteran Universitas Sam Ratulangi, \\ Manado, Sulawesi Utara, Indonesia \\ Email: jessicafrorrong@gmail.com
}

\begin{abstract}
Nausea and vomiting are common problems in early pregnancy. Symptoms of nausea and vomiting in pregnant women that persist and get worse are called hyperemesis gravidarum. The causes of hyperemesis gravidarum are not exactly known, but it is supposed that they could be caused inter alia by psychological factors. This study was aimed to determine the relationship between the psychological state of pregnant women and the incidence of hyperemesis gravidarum. This was a literature review study by using three databases, namely Google Scholar, ClinicalKey, and Pubmed. The keywords used were psychological AND hyperemesis gravidarum. The result showed that the psychological conditions assessed in most literatures were anxiety disorders, depression, and stress. Pregnant women who suffered from anxiety and stress could trigger or worsen the depression. The higher level of anxiety would increase the chance of suffering from hyperemesis gravidarum. Therefore, pregnant women need additional psychological support during treatment and as a follow-up for pregnant women with hyperemesis gravidarum. In conclusion, the psychological state of pregnant women is related to the incidence of hyperemesis gravidarum.
\end{abstract}

Keywords: psychological, hyperemesis gravidarum, nausea and vomiting

\begin{abstract}
Abstrak: Mual dan muntah merupakan masalah yang biasa terjadi pada awal kehamilan. Gejala mual dan muntah pada ibu hamil yang menetap dan bahkan bertambah berat disebut hiperemesis gravidarum. Faktor pemicu terjadinya hiperemesis gravidarum pada ibu hamil belum diketahui secara pasti, tetapi diperkirakan antara lain oleh faktor psikologis. Penelitian ini bertujuan untuk mengetahui hubungan keadaan psikologis ibu hamil dengan kejadian hiperemesis gravidarum. Jenis penelitian ialah literature review dengan pencarian data menggunakan tiga database yaitu Google Scholar, ClinicalKey, dan Pubmed. Kata kunci yang digunakan yaitu psikologis Ipsychological AND hiperemesis gravidarum/hyperemesis gravidarum. Hasil penelitian mendapatkan bahwa kondisi psikologis yang dinilai pada sebagian besar literatur yang dikaji ialah mengenai gangguan kecemasan, depresi, dan stres. Ibu hamil yang mengalami cemas dan stres dapat memicu atau memperburuk terjadinya depresi. Tingkat kecemasan yang semakin tinggi akan meningkatkan peluang untuk mengalami hiperemesis gravidarum sehingga diperlukan dukungan psikologis tambahan selama perawatan dan sebagai tindak lanjut ibu hamil dengan hiperemesis gravidarum. Simpulan penelitian ini ialah keadaan psikologis ibu hamil berhubungan dengan kejadian hiperemesis gravidarum.
\end{abstract}

Kata kunci: psikologis, hiperemesis gravidarum, mual dan muntah

\section{PENDAHULUAN}

Menurut Federasi Obstetri Ginekologi Internasional, kehamilan adalah fertilisasi atau penyatuan dari spermatozoa dan ovum yang dilanjutkan dengan nidasi atau tertanamnya hasil pembuahan ke dalam endometrium. Normalnya, kehamilan berlangsung selama 9 bulan menurut kalender 
internasional atau 40 minggu, dan terbagi menjadi 3 trimester. Saat kehamilan, terjadi perubahan produksi dan pengaruh hormonal, perubahan anatomik, dan perubahan fisiologik. ${ }^{1}$ Mual dan muntah ialah masalah yang biasa terjadi pada awal kehamilan. Sekitar 50-75\% ibu hamil mengalami mual dan muntah. Sekitar $25 \%$ hanya mengalami mual, dan $50 \%$ mengalami baik mual maupun muntah. ${ }^{2}$ Gejala mual dan muntah biasanya memburuk saat pagi atau biasa disebut morning sickness. Namun, mual dan muntah tersebut dapat terjadi pada siang ataupun malam hari. ${ }^{3}$ Walaupun beberapa orang beranggapan bahwa, mual dan muntah merupakan hal yang normal dalam kehamilan, banyak wanita yang merasa bahwa mual dan muntah ini memengaruhi kualitas hidup, berkontribusi terhadap tingginya depresi, dapat menegangkan hubungan keluarga, dan menjadi beban ekonomi. ${ }^{4}$

Seorang ibu hamil yang mengalami hiperemesis gravidarum akan mengalami mual dan muntah yang begitu hebat sehingga segala yang dimakan dan diminum dimuntahkan. Keadaan ini menyebabkan terganggunya pekerjaan sehari-hari, bahkan mengalami dehidrasi, dan penurunan berat badan. ${ }^{5}$ Hiperemesis gravidrum oleh Hyperemesis Education and Research Foundation, digambarkan sebagai penyakit kehamilan yang melemahkan dan berpotensi mengancam nyawa yang ditandai dengan penurunan berat badan yang cepat, malnutrisi, dan dehidrasi karena mual dan muntah yang tak henti dengan potensi yang merugikan bagi ibu dan bayi yang baru lahir. ${ }^{6}$ World Health Organization (WHO), pada tahun 2007 menyebutkan bahwa jumlah kejadian hiperemesis gravidarum mencapai $12.5 \%$ dari seluruh kehamilan di dunia. Berdasarkan Departemen Kesehatan Republik Indonesia tahun 2013, jumlah wanita yang mengalami kehamilan ialah 5.212.568 orang, dan ibu hamil yang mengalami kejadian hiperemesis gravidarum mencapai $14.8 \% .^{7}$

Faktor pemicu terjadinya hiperemesis gravidarum pada ibu hamil belum diketahui secara pasti, tetapi diperkirakan oleh karena beberapa hal, seperti faktor hormonal, psi- kologis, paritas, nutrisi dan alergi, genetik, usia, aktivitas, dan bakteri Helicobacter pylori. ${ }^{1,8}$ Adanya masalah psikologis pada ibu hamil dapat menjadi predisposisi dalam mengalami mual dan muntah yang kemudian memburuk. Masalah emosional juga berkaitan dengan kejadian mual dan muntah menjadi lebih berat. ${ }^{9}$ Faktor psikologis yang mungkin berpengaruh ialah adanya cemas, stres, atau depresi. Hal ini merupakan reaksi dari tubuh dalam menghadapi situasi yang tidak biasa, seperti situasi yang membahayakan, merisaukan, dan membingungkan seseorang. ${ }^{10}$

\section{METODE PENELITIAN}

Penelitian ini berbentuk suatu literature review. Pencarian data penelitian ini menggunakan tiga database yaitu Google Scholar, ClinicalKey, dan Pubmed. Kata kunci yang digunakan yaitu psikologis/psychological AND hiperemesis gravidarum/hyperemesis gravidarum.

\section{HASIL PENELITIAN}

Berdasarkan hasil pencarian literatur pada tiga database, didapatkan sebanyak 942 literatur menggunakan Google Scholar, 115 literatur menggunakan ClinicalKey, dan 51 literatur menggunakan PubMed ( $\mathrm{n}=$ 1108). Selanjutnya, dilakukan skrining berdasarkan judul yang sesuai dengan tema penelitian dan didapatkan 219 literatur. Sebanyak 100 ar literatur tikel dieksklusi karena tidak tersedia full text, dan didapatkan 119 literatur $(\mathrm{n}=119)$. Setelah dilakukan skrining abstrak dan full text dari ke 119 literatur tersebut berdasarkan kriteria inklusi dan ekslusi, maka didapatkan 14 literatur $(n=14)$. Berdasarkan hasil seleksi literatur didapatkan enam literatur melakukan penelitian cross sectional, lima penelitian case control, satu penelitian longitudinal, dan dua penelitian cohort.

\section{BAHASAN}

Masalah psikologis sangat umum terjadi pada wanita hamil. Hal ini terjadi karena kehadiran janin di dalam tubuh seorang ibu membawa perubahan yang berpengaruh pada kondisi psikologis ibu. 
Tabel 1. Hasil kajian dari literatur yang digunakan dalam penelitian

\begin{tabular}{|c|c|c|c|c|}
\hline No & Peneliti & $\begin{array}{c}\text { Jenis } \\
\text { Penelitian }\end{array}$ & $\begin{array}{l}\text { Ukuran } \\
\text { Sampel }\end{array}$ & Hasil Penelitian \\
\hline 1. & $\begin{array}{l}\text { Simsek et al, } \\
2011^{11}\end{array}$ & Case-control & 86 & $\begin{array}{l}\text { Rerata skor BDI dan BAI pasien hiper- } \\
\text { emesis gravidarum lebih tinggi diban- } \\
\text { dingkan kontrol }(\mathrm{p}=0,0001 \text { dan } \mathrm{p}=0,049) \text {. }\end{array}$ \\
\hline 2. & $\begin{array}{l}\text { Sulistyowati } \\
\text { et al, } 2012^{12}\end{array}$ & Longitudinal & 79 & $\begin{array}{l}\text { Hubungan antara tingkat stres dengan } \\
\text { kejadian hiperemesis pada ibu hamil } \\
\text { trimester I didapatkan } \mathrm{p}=0,000 \text {. }\end{array}$ \\
\hline 3. & $\begin{array}{l}\text { Uguz et al, } \\
2012^{13}\end{array}$ & Case-control & 142 & $\begin{array}{l}\text { - Hubungan pasien dengan hiperemesis } \\
\text { gravidarum dan gangguan mood ialah } \\
\mathrm{p}=0,000 \text {, } \\
\text { - Hubungan pasien dengan hiperemesis } \\
\text { gravidarum dan gangguan kecemasan } \\
\text { menyeluruh didapatkan } \mathrm{p}=0,001 \text {, } \\
\text { - Hubungan pasien dengan hiper-emesis } \\
\text { gravidarum dan secara spesifik yaitu } \\
\text { depresi mayor ialah } \mathrm{p}=0,031 \text {, }\end{array}$ \\
\hline 4. & Fitrina, $2014^{14}$ & Cross sectional & 51 & $\begin{array}{l}\text { Hubungan tingkat kecemasan pada ibu } \\
\text { hamil trimester } 1 \text { dengan kejadian hiper- } \\
\text { emesis gravidarum didapatkan } \mathrm{p}=0,022\end{array}$ \\
\hline 5. & $\begin{array}{l}\text { Magtira et al, } \\
2014^{15}\end{array}$ & Case-control & 108 & $\begin{array}{l}\text { Kondisi kejiwaan yang sudah ada sebe- } \\
\text { lumnya tidak berperan dalam risiko } \\
\text { hiperemesis gravidarum. }(\mathrm{p}=0,08)\end{array}$ \\
\hline 6. & $\begin{array}{l}\text { Tan et al, } \\
2014^{16}\end{array}$ & Cohort & 129 & $\begin{array}{l}\text { Wanita yang dirawat di rumah sakit } \\
\text { dengan hiperemesis gravidarum pada } \\
\text { trimester ketiga untuk depresi, kece- } \\
\text { masan, dan stres masing-masing ialah } \\
\text { p }<0,001 \text {. }\end{array}$ \\
\hline 7. & $\begin{array}{l}\text { Aksoy et al, } \\
2015^{17}\end{array}$ & Case-control & 160 & $\begin{array}{l}\text { Rerata skor BDI dalam studi hiperemesis } \\
\text { gravidarum lebih tinggi dibandingkan } \\
\text { kelompok kontrol yang sehat }(\mathrm{p}<0,001) \text {. }\end{array}$ \\
\hline 8. & Putri, $2015^{18}$ & Cross sectional & 50 & $\begin{array}{l}\text { Hubungan antara stres dengan kejadian } \\
\text { hiperemesis gravidarum berat didapat- } \\
\text { kan } p=0,019\end{array}$ \\
\hline 9. & $\begin{array}{l}\text { Kjeldgaard et } \\
\text { al, } 2016^{19}\end{array}$ & Cohort & 81,786 & $\begin{array}{l}\text { Hubungan riwayat depresi dengan } \\
\text { hiperemesis gravidarum didapatkan } \\
\mathrm{p}<0,001 \text { dan untuk gejala depresi saat ini } \\
\text { didapatkan } \mathrm{p}<0,001\end{array}$ \\
\hline 10. & $\begin{array}{l}\text { Ratnasari et } \\
\text { al, } 2016^{20}\end{array}$ & Cross sectional & 45 & $\begin{array}{l}\text { Hubungan tingkat stres dengan kejadian } \\
\text { hiperemesis gravidarum pada primi- } \\
\text { gravida didapatkan } \mathrm{p}=0,004\end{array}$ \\
\hline 11. & Safari, $2017^{21}$ & Cross sectional & 32 & $\begin{array}{l}\text { Hubungan psikologis ibu dengan } \\
\text { hiperemesis gravidarum di RSUD h. Abd. } \\
\text { Manan Simatupang kisaran tahun } 2017 \\
\text { didapatkan } \mathrm{p}=0,000 \text {. }\end{array}$ \\
\hline 12. & $\begin{array}{l}\text { Kartikasari, } \\
2018^{9}\end{array}$ & Cross sectional & 28 & $\begin{array}{l}\text { Hubungan derajat kecemasan deengan } \\
\text { kejadian mual dan muntah didapatkan } \\
\mathrm{p}=0,000\end{array}$ \\
\hline 13. & $\begin{array}{l}\text { Syamsuddin } \\
\text { et al, } 2018^{10}\end{array}$ & Cross sectional & 74 & $\begin{array}{l}\text { Hubungan antara stres dengan hiper- } \\
\text { emesis gravidarum didapatkan } p=0,044 \text {. }\end{array}$ \\
\hline 14. & $\begin{array}{l}\text { Yildirim et al, } \\
2019^{22}\end{array}$ & Case-control & 98 & $\begin{array}{l}\text { - Hubungan antara skor BAI dan hiper- } \\
\text { emesis gravidarum ialah } \mathrm{p}<0,001 \text {. } \\
\text { - Hubungan antara skor BDI dan } \\
\text { hiperemesis gravidarum ialah } \\
\text { p<0,001. }\end{array}$ \\
\hline
\end{tabular}


Kondisi psikologis yang mengalami gangguan dapat berubah bentuk menjadi gangguan fisik, salah satunya ialah hiperemesis gravidarum. ${ }^{11,12}$ Keadaan ini terjadi berkaitan dengan ketidakseimbangan cairan dan makanan yang dapat mengarah ke dehidrasi, ketidakseimbangan elektrolit dan asam basa, defisiensi nutrisi, ketonuria dan penurunan berat badan. ${ }^{1}$

Gangguan depresi merupakan salah satu yang sering dijumpai pada wanita hamil saat pemeriksaan antenal, dan dapat ditangani menggunakan intervensi psikososial. Sering pula dijumpai ibu hamil dengan depresi berat yang jika tidak ditangani, depresi akan berlanjut hingga postpartum. ${ }^{23}$ Penelitian oleh Kjeldgaard et $\mathrm{al}^{19}$ dengan berbasis populasi, mendapatkan $29,9 \%$ ibu hamil dengan hiperemesis gravidarum memiliki riwayat depresi. Hasil penelitian oleh Simsek ${ }^{11}$ di Malatya, Turkey yang menggunakan BDI-21 didapatkan nilai rerata pada pasien hiperemesis gravidarum ialah 20,9 secara bermakna lebih tinggi dibandingkan kontrol dengan rerata 11,8. Pada penelitian Aksoy et $\mathrm{al}^{17}$ di Turkey, didapatkan rerata BDI-21 pada pasien hiperemesis gravidarum ialah 18,97 . Hal ini sejalan dengan penelitian oleh Yildirim ${ }^{22}$ di Turkey, yang mendapatkan rerata skor BDI 17,84 pada pasien hiperemesis gravidarum. Berdasarkan penelitian-penelitian tersebut, didapatkan ibu hamil dengan hiperemesis gravidarum sebagian besar memiliki tingkat depresi sedang. ${ }^{24}$

Masalah psikologis lainnya yang sering ditemukan pada ibu hamil ialah kecemasan dan stres yang memicu atau memperburuk terjadinya depresi. ${ }^{25,26}$ Faktor-faktor penyebab timbulnya kecemasan di antaranya cemas akan tanggung jawab dan dukungan dari lingkungan sosial. Pengetahuan yang kurang akan menimbulkan kecemasan karena takut tidak dapat merawat anaknya nanti. Hal ini selaras dengan penelitian oleh Fitrina $^{14}$ dengan responden sebagian besar sedang dalam kehamilan anak pertama, dan seluruh responden masuk dalam kategori berpendidikan rendah yaitu hanya sampai tingkat SD, SMP, dan SMA. ${ }^{14}$ Penyebab lain dari timbulnya kecemasan pada ibu hamil ialah perasaan bersalah, mengasihani diri sendiri, dan adanya konflik yang serius. ${ }^{11}$

Sulistyowati $^{12}$ dalam penelitiannya dengan metode analitik korelasi dan pendekatan longitudinal menyebutkan bahwa sebanyak 70,9\% stres yang dialami oleh responden disebabkan oleh ketakutan tanpa alasan yang jelas. ${ }^{1}$ Pada penelitian yang dilakukan oleh Putri ${ }^{18}$ terhadap 50 ibu hamil dengan hiperemesis gravidarum, didapatkan sebanyak 38 responden mengalami stres, 21 responden mengalami hiperemesis gravidarum ringan, dan 17 responden mengalami hiperemesis gravidarum sedang.

Pada penelitian oleh Fitrina, ${ }^{14}$ dilakukan wawancara dengan ibu hamil, dan didapatkan ibu hamil sering merasa cemas yang ditandai dengan gelisah, perasaan tidak menentu, dan sering bertanya kepada petugas kesehatan mengenai kehamilannya. Selain itu, berdasarkan hasil kuesioner didapatkan dari 31 ibu hamil dengan hiperemesis gravidarum sebanyak 2 responden mengalami tingkat kecemasan ringan, 22 responden mengalami tingkat kecemasan sedang, dan 6 responden mengalami tingkat kecemasan berat. Penelitian oleh Uguz et al ${ }^{13}$ mendapatkan sebanyak 8 dari 52 pasien dengan hipermesis gravidarum didiagnosis generalized anxiety disorder (GAD).

Pengukuran tingkat kecemasan dapat dilakukan melalui beberapa kuesioner, salah satunya ialah BAI. ${ }^{24}$ Penelitian oleh Simsek et $\mathrm{a}^{11}$ menggunakan BAI dan mendapatkan rerata skor BAI pada penderita hiperemesis gravidarum yaitu 18,5 lebih tinggi daripada kontrol yaitu 13,6. Pada penelitian Yildirim $^{22}$ didapatkan rerata skor BAI pada pasien dengan hiperemesis gravidarum ialah 23,36 lebih tinggi daripada kontrol yaitu 9,11. Berdasarkan kedua penelitian tersebut, didapatkan tingkat kecemasan pada ibu hamil dengan hiperemesis gravidarum ialah sedang. Menurut penelitian oleh Kartikasari ${ }^{9}$ di Lamongan, tingkat kecemasan yang tinggi pada ibu hamil menyebabkan mual dan muntah semakin berat yang dapat menyebabkan hiperemesis gravidarum. Hal ini juga sejalan dengan penelitian oleh Fitrina ${ }^{14}$ yang berkesimpulan bahwa tingkat kecemasan yang semakin tinggi akan 
meningkatkan peluang untuk mengalami hiperemesis gravidarum.

Wanita dengan kecemasan atau stres semasa kehamilan memiliki tingkat aborsi spontan yang tinggi dan meningkatkan terjadinya kelahiran prematur. Selain itu, jika seorang ibu mengalami stres yang berat pada masa kehamilan, anaknya lebih mungkin untuk mengalami masalah emosional dan kognitif. ${ }^{11}$ Oleh karena itu, diagnosis dini hiperemesis gravidarum sangat diperlukan secara klinis. Hal ini juga untuk menghindari berbagai komplikasi yang mungkin terjadi seperti defisiensi vitamin B1 dan K pada ibu, ensefalopati Wernicke pada janin, kelahiran prematur, intrauterine growth restriction (IUGR), dan gangguan kejiwaan pada masa dewasa. ${ }^{27}$ American College of Obstetricians and Gynecologist (ACOG) menyarankan agar pengobatan dini segera dilakukan untuk mencegah menjadi lebih parah. Terapi lini pertama secara nonfarmakologi untuk mual dan muntah saat hamil dan hiperemesis gravidarum ialah modifikasi pola makan seperti konsumsi makanan rendah lemak, rendah serat, dan hambar (roti, kerupuk, sereal, telur, tahu, selain kacang, buah-buahan, dan sayuran ${ }^{2}$ Selain itu, terdapat pengobatan alternatif yaitu dengan jahe. Penelitian saat ini menunjukkan bahwa jahe sangat aman dalam kehamilan. ${ }^{4}$ Selain itu, dukungan psikologis tambahan juga diperlukan selama perawatan dan sebagai tindak lanjut ibu hamil dengan hiperemesis gravidarum. ${ }^{11}$

\section{SIMPULAN}

Keadaan psikologis pada ibu hamil berhubungan dengan kejadian hiperemesis gravidarum.

\section{Konflik Kepentingan}

Penulis menyatakan tidak terdapat konflik kepentingan dalam studi ini.

\section{DAFTAR PUSTAKA}

1. Prawirohardjo S. Ilmu Kebidanan Sarwono Prawirohardjo (4th ed). Jakarta: Yayasan Bina Pustaka Sarwono Prawirohardjo. 2016.

2. Martonffy AI, Rindfleisch K, Lozeau AM,
Potter B. First trimester complications. Prim Care Clin Off Pract. 2020;39(1): 71-82. Available from: http://dx.doi. org/10.1016/j.pop.2011.11.004

3. Festin M. Nausea and vomiting in early pregnancy. Am Fam Physician. 2015; 92(6):516-7.

4. Pontius E, Vieth JT. Complications in Early Pregnancy. Emerg Med Clin NA. 2019; 37(2):219-37. Available from: https:// doi.org/10.1016/j.emc.2019.01.004

5. Tan PC, Vani S, Lim BK, Omar SZ. Anxiety and depression in hyperemesis gravidarum: prevalence, risk factors and correlation with clinical severity. Eur J Obstet Gynecol. 2020;149(2):153-8. Available from: http://dx.doi.org/10. 1016/j.ejogrb.2009.12.031

6. Ayyavoo A, Derraik GB, Hofman PL, Cutfield WS. Hyperemesis gravidarum and longterm health of the offspring. Am J Obstet Gynecol. 2014;210(6):521-5

7. Butu Y, Rottie J, Bataha Y. Faktor-faktor yang berhubungan dengan kejadian hiperemesis gravidarum pada ibu hamil trimester I. eJournal Keperawatan. 2019;7(2):1-2.

8. Rofi'ah S, Widatiningsih S, Arfiana. Studi fenomenologi kejadian hiperemesis gravidarum pada ibu hamil trimester 1 . $\mathbf{J}$ Ris Kesehat. 2019;8(1):41-52.

9. Kartikasari RI. Derajat kecemasan ibu hamil dengan kejadian mual muntah pada trimester 1. J Ris Kebidanan Indones. 2018;2(2):69-74.

10. Syamsuddin S, Lestari H, Fachlevy AF. Hubungan antara gastritis, stres, dan dukungan suami pasien dengan sindrom hiperemesis gravidarum di wilayah kerja Puskesmas Poasia Kota Kendari. J Penelit dan Pengemb Pelayanan Kesehat. 2018;2(2):102-7.

11. Şimşek Y, Çelik Ö, Yilmaz E, Karaer A, Yildirim E, Yoloğlu S. Assessment of anxiety and depression levels of pregnant women with hyperemesis gravidarum in a case-control study. J Turkish Ger Gynecol Assoc. 2012;13(1):32-6.

12. Sulistyowati, Soesanto E, Purwanti I. Hubungan antara tingkat stres dengan kejadian hiperemesis gravidarum pada ibu hamil trimester i di BPS Ny. Sayidah Kendal. Jurnal Kebidanan. 2014;3(1):14-8. Available from: http://jurnal.unimus. ac.id/index.php/jur_bid/article/viewFile 
$/ 1074 / 1123$

13. Uguz F, Gezginc K, Kayhan F, Cicek E, Kantarci AH. Is hyperemesis gravidarum associated with mood, anxiety and personality disorders: a case-control study. Gen Hosp Psychiatry. 2012; 34(4):398-402. Available from: http:// dx.doi.org/10.1016/j.genhosppsych.201 2.03.021

14. Fitrina Y. Hubungan tingkat kecemasan ibu hamil trimester 1 dengan kejadian hiperemesis gravidarum di wilayah kerja Puskesmas Palembayan Jorong Koto Tinggi tahun 2014. Jurnal Ilmu Kesehatan 'Afiyah.' 2015;2(1):1-8.

15. Magtira A, Paik Schoenberg F, MacGibbon K, Tabsh K, Fejzo MS. Psychiatric factors do not affect recurrence risk of hyperemesis gravidarum. J Obstet Gynaecol Res. 2014;41(4):512-6.

16. Tan PC, Zaidi SN, Azmi N, Omar SZ, Khong SY. Depression, anxiety, stress and hyperemesis Gravidarum: Temporal and case controlled correlates. PLoS One. 2014;9(3):e92036.

17. Aksoy H, Aksoy Ü, Karadağ Öİ, Hacimusalar Y, Açmaz G, Aykut G, et al. Depression levels in patients with hyperemesis gravidarum: a prospective case-control study. Springerplus. 2015;4(1):2-7.

18. Putri AM. Hubungan stress dengan kejadian hiperemesis gravidarum pada ibu hamil di RSUD Dr .A . Dadi Tjokrodipo , RSUD Dr . H . Abdul Moeloek dan RS Bintang Amin. 2015;2(4):194-9.

19. Kjeldgaard HK, Eberhard-Gran M, Benth JŠ, Nordeng H, Vikanes ÅV. History of depression and risk of hyperemesis gravidarum: a population-based cohort study. Arch Womens Ment Health. 2017;20(3):397-404.

20. Ratnasari MY, Girsang BM, Nastosba J. Hubungan tingkat stres dengan kejadian hiperemesis gravidarum pada primigravida. Progr Stud Ilmu Keperawatan Fakultas Kedokteran Universitas Sriwijaya. 2016;110. Available from: https://www.academia.edu/35801769/H
UBUNGAN_TINGKAT_STRESS_D

ENGAN_KEJADIAN_HIPEREMESI

S_GRAVIDARUM_PADA_PRIMIG

RAVIDA

21. Safari F. Hubungan karakteristik dan psikologis ibu hamil dengan hiperemesis gravidarum di RSUD H. Abd. Manan Simatupang Kisaran. WAHANA Inov. 2017;6(1):201-10.

22. Yıldırım E, Demir E. The relationship of hyperemesis gravidarum with sleep disorders, anxiety and depression. $\mathbf{J}$ Obstet Gynaecol (Lahore). 2019;39(6): 793-8. Available from: https://doi.org/ 10.1080/01443615.2019.1572725

23. Schofield Z, Sisoda N. An obstetrician's guide to perinatal psychiatry. Obstet Gynaecol Reprod Med. 2014;24(11):340-4. Available from: http://dx.doi.org/10. 1016/j.ogrm.2014.08.003

24. Grant MM. Beck Anxiety Inventory. In: Goldstein S, Naglieri JA, editors. Encyclopedia of Child Behavior and Development. Boston: Springer, 2011; p. 1-5. Available from: https:// doi.org/10.1007/978-0-387-790619_3159

25. Emami-sahebi A, Elyasi F, Yazdani-charati J, Shahhosseini Z. Psychological interventions for nausea and vomiting of pregnancy: a systematic review. Taiwan J Obstet Gynecol. 2018;57(5):644-9. Available from: https://doi.org/10.1016/ j.tjog.2018.08.005

26. Thorsness KR, Watson C, Larusso EM. Perinatal anxiety : approach to diagnosis and management in the obstetric setting. Am J Obstet Gynecol. 2018;219(4): 326-45. Available from: https://doi.org/ 10.1016/j.ajog.2018.05.017

27. Ioannidou P, Papanikolaou D, Mikos T, Mastorakos G, Goulis DG. Predictive factors of Hyperemesis Gravidarum : A systematic review. Eur J Obstet Gynecol Reprod Biol. 2019;238:178-87. Available from: https://doi.org/10.1016/ j.ejogrb.2019.04.043. 